\title{
The Nutritional Requirements of the Chick
}

\author{
Albert G. Hogan and Robert V. Boucher
}

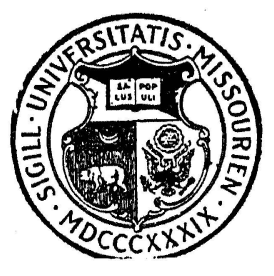




\section{Agricultural Experiment Station}

EXECUTIVE BOARD OF CURATORS.-MERCER ARNOLD, JOplin; F. M. MCDAVID, Springfield; H. J. BLANTON, Paris

ADVISORY COUNCIL.-THE MISSOURI STATE BOARD OF AGRICULTURE

STATION STAFF, JUNE 1933

WALTER WILLIAMS, LL. D., President

F. B. MUMFORD, M. S., D. Agr., Director $\quad$ S. B. SHIRKY, A. M., Asst. to Director MISS ELLA PAHMEIER, Secretary

AGRICULTURAL CHEMISTRY

A. G. HogAN, Ph.D.

L. D. HAIGE, Ph.D.

W. W. Cowan, A.M.

ROBERT BOUCHER, JR., A.M.

LUther R. Richardson, Ph.D.

U. S. AsHWORTH, A.B.

\section{AGRICULTURAL ECONOMICS}

O. R. JoHnson, A.M.

BEN H. FRAME, A.M.

F. L. THOMSEN, Ph.D.

C. H. HAMMar, Ph.D.

\section{AGRICULTURAL ENGINEERING}

J. C. WOOLEY, M.S.

MaCx M. Jones, M.S.

R. R. PARKS, A.M.

D. D. SMIth, A.M.

\section{ANIMAL HUSBANDRY}

E. A. Trowbridge, B.S. in Agr.

L. A. Weaver, B.S. in Agr.

A. G. Hogan, Ph.D.

F. B. MUMFord, M.S., D. Agr.

D. W. CHITTENDEN, A.M.

F. F. McKenzie, Ph.D.*

J. Comfort, A.M.*

H. C. MOFFETT, A.M.

Ralph W. PhILIIPS. A.M.

S. R. Jornson, A.M.

C. E. TERRILI. B.S.

\section{BOTANY AND PATHOLOGY}

W. J. Robins, Ph.D.

\section{DAIRY HUSBANDRY}

A. C. RagsDale, M.S.

WM. H. E. REID, A.M.

SAMUEI BRODY, Ph.D.

C. W. Turner, Ph.D.

WARREN GIFFORD, A.M.†

E. R. Garrison, A.M.

H. A. Herman, A.M.

M. N. Hales, B.S.

WARREN C. HALL, A.M.

HAROLD ALIEY, B.S.

WILLIAM E. EckLEs, B.S.

ENTOMOLOGY

Leonard Haseman, Ph.D

T. E. BIRKETT, A.M

FIELD CROPS

W. C. ETHERIDGe, Ph.D.

C. A. HeLM, A.M.*

*In cooperative service with the U. S Department of Agriculture.
L. J. Stadler, Ph.D.*

R. T. KIRKPATRICK, A.M.

B. M. KING, A.M.*

E. MARION BRown, A.M.*

Miss Ciara FuHR, M.S.*

\section{HOME ECONOMICS}

Mabel Campeeli, A.M.

Jessie Alice Cline, A.M.

AdELla EPPEL Ginter, M.S.

Sylvia Cover, A.M.

HELEN BERESFORD, B.S.

Bertha Bisbey, Ph.D.

Jessie V. Coles, Ph.D.

MINERVA V. GRACE, M.S.

Frances SeEds, M.S.

BERTHA K. WhipPLE, M.S.

\section{HORTICULTURE}

T. J. TALBERT, A.M.

A. E. MurneEk, Ph.D.

H. G. Swartwout, A.M.

Gio. Carl Vinson, Ph.D.

POULTRY HUSBANDRY

H. L. KeMPSTER, M.S.

E. M. FUN A, A.M.

\section{RURAL SOCIOLOGY}

E. L. Morgan, A.M.

WALTER BURR, A.M.

HeNRY J. BURT, A.M.

ARTHUR S. EMIG, Ph.D.

\section{SOILS}

M. F. MrLLER, M.S.A.

H. H. KRUSEXOPF, A.M.

W. A. ALBRECHT, Ph.D.

HANS JENNY, Ph.D.

L. D. BAVER, Ph.D.

HAROLD F. RHOADES, A.M.

VETERINARY SCIENCE

A. J. Durant, A.M., D.V.M.

J. W. Connaway, D.V.M., M.D.

CECIL ELDER, A.M., D.V.M.

O. S. Crisler, D.V.M.

ANDREW UREN, D.V.M.

A. M. MCCAPES, D.V.M.

Haroid C. MCDOUgle, A.M.

OTHER OFFICERS

R. B. PrICE, B.L., Treasurer

LeSLIE Cowan, B.S., Sec'y of University

A. A. JEFFrEY, A.B., Agricultural Editor

J. F. BARHAM, Photographer

Jan e Frodsham, Librarian

tOn leave of absence. 


\title{
The Nutritional Requirements of the Chick
}

\author{
Albert G. Hogan and Robert V. Boucher
}

\begin{abstract}
A synthetic diet that contains the usual percentage of yeast is inadequate for the chick. Such a ration is not improved by increasing the allowance of vitamins $A$ and $D$, but is improved by increasing the allowance of yeast.

Various soluble supplements were examined in an attempt to discover one that contains the factor in which yeast is deficient. The ether-extract of egg yolk and tikitiki offered some promise, and acid-hydrolyzed yeast was extremely promising. An extract of liver contains the factor sought but rather large quantities, $10 \%$ of the ration, are required to make the ration adequate.

An attempt was made to use a water extract of yeast instead of yeast itself. Even when this extract made up $20 \%$ of the entire ration it did not prove reliable. The factors in which the water extract is deficient are supplied by a combination of acid-hydrolyzed yeast and ether-extract of egg yolk.

A successful attempt was made to formulate a ration which contains all the vitamins in soluble form. The vitamin carriers are acid-hydrolyzed yeast, the ether-extract of egg yolk, a liver extract, and tikitiki. This mixture has proven adequate for chicks through one generation, and the second generation of pullets has just begun laying.

It is believed that each of the vitamin carriers contains an essential factor which is not present in the others in large amounts. Some of these carriers undoubtediy contain more than one factor, however, so it is impossible to determine the total number until further concentration and isolation is achieved. This is no longer impossible, since all the supplements are soluble, either in water or in ether.
\end{abstract}

The use of simplified diets is essential for the solution of certain types of problems that arise in nutritional investigations, but so far as we are aware no one has attained more than partial success in rearing any animal except the rat or mouse on rations of that type. This proved to be a serious obstacle in our studies on the nutritional requirements of the chick, so for several years we have been attempting to formulate a simplified diet that is adequate for this species. Hogan, Guerrant, and Kempster ${ }^{1}$ demonstrated that it is perfectly feasible to rear chicks under laboratory conditions if the ration is properly adjusted, but they found that simplified diets adequate for the rat are grossly deficient for the chick. Simplified diets that had proven satisfactory for the rat were then mixed with natural foodstuffs, taking care that the final chemical composition and physical texture were not changed in any important degree. When the natural foodstuff was finely powdered egg yolk, or polished rice, the chicks grew rapidly and were normal in appearance. McFarlane, Graham, and $\mathrm{Hall}^{2}$ have confirmed this observation on polished rice, but some of our later unpublished ob- 
servations have convinced us that this material is more variable than we had at first supposed. However that may be, it seems certain that the inadequacy of simplified diets for the chick is not due to any maladjustment that can be detected by the conventional chemical analysis, or to the physical texture of any of the constituents. It seemed possible that the chick may require larger quantities of vitamins $A, B$, and $D$ than does the rat, so the amounts of yeast and cod liver oil in the basal diet were increased. The increase in cod liver oil was of no value, and the improvement due to larger amounts of yeast was limited and inconsistent. Orange juice and wheat germ oil were also included in the ration, in unpublished trials, to see if the chick requires either vitamin $\mathrm{C}$ or vitamin $\mathrm{E}$ for growth. Neither supplement reduced the proportion of failures, and these vitamins have been disregarded in subsequent studies.

Hogan and Shrewsbury ${ }^{3}$ did not succeed in formulating a simplified diet that is adequate for the chick, but some of their contributions were helpful in our extension of this field. They observed that if a ration contains very large percentages of yeast, as much as $40 \%$, chicks can grow normally. They observed also that if a water extract of yeast is supplied at a very high level, $20 \%$ for example, the ration is usually adequate. These observations were interpreted as showing that one of the essential factors of yeast is either not soluble in water, or is in chemical combination with some insoluble substance of yeast. They were also interpreted as showing that the inadequacy is due to an important difference between the rat and chick, either in the quantity, or number, of the vitamins which they require. It would seem that this difference must lie in the requirement for certain members of the vitamin $B$ complex, for no other vitamin has been recognized as consistently present in yeast. It will be understood that our position does not imply that all these members are soluble in water.

The question arises then, what yitamins are included in the vitamin $\mathrm{B}$ complex? This is a controversial point, but according to $\mathrm{Peters}^{4}$ there are not less than 5 or $6 . \mathrm{B}_{1}, \mathrm{~B}_{3}$, and $\mathrm{B}_{5}$ are required by the pigeon, and $B_{1}, B_{2}, B_{4}$, and $Y$ are required by the rat. How many of these are required by the chick is unknown, but there is no doubt that besides them the chick requires vitamins $A$ and $D$, and that it does not require vitamin $\mathrm{C}$.

The nature of the abnormalities which chicks exhibit, when reared on deficient diets, requires more than passing mention. We have divided those commonly observed in this laboratory into two 
classes, neuritis and leg weakness or paralysis. Our primary object has always been to obtain a diet that will prevent abnormalities of any kind, and we have made no extended effort to define more precisely those that did develop. It is possible that the two types of abnormalities which we observed may be further classified into groups of distinctly different origin. On the other hand, we have no convincing evidence that they are not different manifestations of the same deficiency. The two types of symptoms frequently cccur in the same group, at the same time, and on the same ration. Additional support for this view is derived from observations on other species and classes of animals. For example, polyneuritis of the pigeon and beri-beri of man are commonly ascribed to the same deficiency, but their manifestations are quite different. It should be mentioned also that our classification has never implied iclentity with any specific abnormality developed by other animals, though such identity maly exist.

The gross symptoms of "polyneuritis", as we observe it in chicks, are not markedly different from the typical polyneuritis of the pigeon. The first manifestation is a slightly lethargic condition; the bird sits most of the time, and if forced to walk does so with the hock joint partially flexed. This is probably due to developing paralysis in the leg muscles. The next manifestation is retraction of the head. The muscles of the wings may also be partly paralyzed which results in "wing drop" and the wings drag on the floor. The equilibrium is often disturbed. This is manifested by twitching of the eyes, holding of the head to one side, turning round and round, falling when attempting to walk, and in severe cases by retracting the head and turning somersaults backwards, commonly described as "cart wheels". These conditions may continue for several days before death results. If the vitamin $B$ complex is administered in sufficient quantity, soon after the onset is observed, recovery is usually very rapid, but the value of this curative procedure in evaluating vitamin B supplements is doubtful, because spontaneous recoveries often occur. The frequency of spontaneous recoveries seems to be increased if food is witheld and the bird is furnished with an abundance of water.

In spite of the fact that the above mentioned symptoms were similar in many respects to the characteristic polyneuritis of pigeons, there is reason to believe that the two conditions are not identical. It is well known that moderate amounts of yeast prevent polyneuritis of pigeons, but it was pointed out in the paper of Hogan, Guerrant, and Kempster ${ }^{1}$ that these quantities of yeast are of 
little value in preventing the neuritis of the chick. On the other hand, as was shown in this same paper, large quantities of polished rice usually prevent chick neuritis, although this same material is a standard basal diet for the production of pigeon polyneuritis.

On the other hand, there are significant similarities between the symptoms we observe in chicks, and those reported as characteristic of pigeon polyneuritis. Spontaneous recoveries occur in both species. Hogan, Shrewsbury, and Kempster ${ }^{5}$ noted enlarged adrenal glands, and more blood sugar in chicks that had collapsed on synthetic diets, and both of these have been reported in polyneuritic pigeons. McCarrison i states that degeneration of some of the cells of the central nervous system is characteristic of polyneuritis columbarum. Pappenheimer and Goettsch ${ }^{3}$ reported extensive lesions of the cerebellum, and occasionally of the cerebrum, of chicks which were reared on simplified diets. Furthermore, head retraction and "cart wheels" of chicks, that resemble strikingly the symptoms of pigeon polyneuritis, are sometimes observed.

There is every reason to believe the symptoms described by us and by Pappenheimer and Goettsch are identical. Dr. Pappenheimer generously examined the brain of one of our chicks and reported that well marked lesions in the cerebellum were found that appeared to be identical with those he had described. The chick he examined for us exhibited unusually severe head retraction. The observations of Pappenheimer and Goettschs, also those of Norris and collaborators ${ }^{910}$ can be harmonized with ours ${ }^{13}$, but these investigators are unwilling to associate the vitamin $B$ compiex with the abnormalities we have described in the chick. In defense of our position we will point out that in our first paper on this subject ${ }^{1}$ it was stated explicitly that vitamin B was not the only important factor in determining the success or failure of our rations. There was never any reason to suppose that the deficiencies were associated with vitamins $\mathrm{A}, \mathrm{C}, \mathrm{D}$, or $\mathrm{E}$, but from the first the evidence indicated that they were associated with the carriers of vitamin B. At that time it would not have been unreasonable to assume the existence of a new vitamin, but we were unable to isolate such a substance. After it was discovered that vitamin $B$ is a mixture it seemed logical to associate the deficiencies with the vitamin B complex. One is equally free, however, to make some other choice.

The first manifestation of leg weakness is a tendency of the chick to rest on the "hocks", the joint between the tibia and tarso- 
metatarsal bones. Careful examination at this time will usually reveal an inflammation and swelling of one or both of these joints. The enlargement then proceeds rapidly, and the joint may reach twice the normal size. At the same time either the tibiae or tarsometatarsi, or both may show slight bending or twisting in this region. In chicks in which these deformities are very severe the tencon of Achilles may slip out of the normal position where it rests in the groove formed by the condyles of the tibia. This is the condition usually described as "slipped tendon". In less severe cases, if its progress is arrested before the tendon slips or the bones become decidedly crooked, the chick may apparently completely recover. Occasionally the skin in the affected region may become greenish blue, resembling the discoloration that develops after a severe bruise. These conditions usually develop during the third week. At the same time, or without any other symptoms, the toes of either or both feet may be curled inwards, in a very characteristic manner. Norris ${ }^{10}$ regards this as due to a specific deficiency.

The lack of the factor required to prevent neuritic symptoms may not be associated with any of the leg deformities clescribed above, but that is uncertain since some types of leg weakness are not accompanied by deformities of the bones. Before these questions are answered we believe it will be necessary to obtain satisfactory isolation of each vitamin the chick requires.

Before proceeding further it should be mentioned that the abnormalities of chicks have been studied by numerous investigators, and have been designated by a variety of terms. The nomenclature has been summarized in the following outline.

\begin{tabular}{|c|c|c|c|}
\hline Reference & $\begin{array}{c}\text { Designation } \\
\text { of disease }\end{array}$ & Cause & Prevented by \\
\hline Titus ${ }^{11}$ & $\begin{array}{l}\text { Perosis or deforming } \\
\text { leg weakness }\end{array}$ & Vitamin deficiency & Rice bran \\
\hline Bethke et al..$^{12}$ & $\begin{array}{l}\text { Nutritional leg } \\
\text { paralysis }\end{array}$ & Vitamin deficiency & $\begin{array}{c}\text { Milk or autoclaved } \\
\text { yeast }\end{array}$ \\
\hline $\begin{array}{l}\text { Norris et a } 1^{9 \cdot 10} \\
\text { Hart ot }=l_{13}^{13} \\
\text { Hall and King }{ }^{14}\end{array}$ & $\begin{array}{l}\text { Paralysis } \\
\text { Paralysis } \\
\text { Range paralysis } \\
\text { or slipped tendon }\end{array}$ & Vitamin deficiency & Milk \\
\hline Hunter and Funk ${ }^{15}$ & $\begin{array}{l}\text { Slipped tendon } \\
\text { or hock disease }\end{array}$ & $\begin{array}{c}\text { Excess minerals } \\
\text { or wire floors }\end{array}$ & $\begin{array}{l}\text { Oats, reducing min- } \\
\text { eral content of ra- } \\
\text { tion, or solid floors }\end{array}$ \\
\hline Payne et al ${ }^{16}$ & $\begin{array}{l}\text { Slipped tendon or } \\
\text { malformed leg } \\
\text { bones }\end{array}$ & Excess minerals & $\begin{array}{l}\text { Reducing mineral } \\
\text { content of ration }\end{array}$ \\
\hline $\begin{array}{l}\text { Herner and Robin- } \\
\text { son }^{17} \\
\text { Parkhurst and } \\
\text { McMurry } \\
\end{array}$ & $\begin{array}{l}\text { Malformed leg } \\
\text { bones } \\
\text { Rachitic leg weak- } \\
\text { ness }\end{array}$ & $\begin{array}{l}\text { Excess minerals } \\
\text { Excess calcium }\end{array}$ & $\begin{array}{l}\text { Reducing mineral } \\
\text { content of ration } \\
\text { Reducing calcium } \\
\text { content of ration }\end{array}$ \\
\hline
\end{tabular}


Many workers in this field believed the symptoms they were reporting had not been observed before, and so they ascribed them to a new deficiency disease. According to Bethke and Record ${ }^{19}$ there are five different types of leg weakness.

At present there is only one type of leg weakness which has been explained in a way that is satisfactory to any considerable number of observers. This is described both as "hock-disease" and as "slipped tendon" and is supposed to be the result of feeding excessive amounts of calcium or phosphorus, or by some maladjustment in their ratio to each other. This abnormality is of considerable practical importance, and has stimulated numerous efforts to letermine the cause. Attention has been centered largely on the $\mathrm{Ca}: \mathrm{P}$ ratio and according to Hart, Scott, Klein, and Halpin ${ }^{20}$ the optimum ratio is between $2: 1$ and $4: 1$. Bethke, Kennard, Kick, and Zinzalian ${ }^{21}$ report as optimum the wider ratios $3: 1$ to $4: 1$. In contrast to these wide ratios, some of the narrower ones will be cited. Holmes and Pigott ${ }^{22}$ conclude that best results are obtained with a ratio of $1.5: 1.0$. According to Wilgus ${ }^{23}$ the ration should contain not less than $0.66 \%$ of calcium, and not less than $0.5 \%$ of phosphorus. The ratio of calcium to phosphorus may vary between $1.0: 1$ and $2.2: 1$.

In addition to the calcium-phosphorus relationships, various types of leg weakness have been ascribed to the following causes: Excessive amounts of the inorganic salts found in practical poultry rations, over-crowding conditions that may arise from intensive methods of brooding, hardware-cloth floors, lack of exercise, insufficient roughage in the diet, and the lack of various vitamins. It is possible then that the abnormalities mentioned are due to nutritional deficiencies, to an improper adjustment of known nutrients, or to unfavorable environmental conditions. It may be that some workers are ignoring nutritional deficiencies because of a faulty diagnosis of the difficulty, or it may be that others are seeking nutriticnal factors that do not exist:

\section{EXPERIMENTAL}

Single-comb White Leghorn chicks were used exclusively as experimental animals, and were secured from the Department of I'oultry Husbandry or from a commercial hatchery.

Battery type brooders, equipped with electrical heating units, housed the chicks the first four weeks and then they were placed in wire cages 2 feet square. The quarters always had solid floors 
which were covered with a litter of sand. Both the brooders and cages were located in a steam-heated laboratory where the temperature was thermostatically controlled. When the chicks were very young a temperature of 36 to $37^{\circ} \mathrm{C}$. was maintained but this was gradually reduced until at the end of six weeks, when the experiments were discontinued, the temperature was about $25^{\circ} \mathrm{C}$.

The chicks were weighed, transferred to the brooders, and fed and watered when one day old. From that time until the end of the experiment both food and water were constantly available. Water was supplied in the common inverted drinking fountains and the food was placed in metal cups suspended at a convenient height. This prevented scratching the food out of the containers and reduced the amount of waste to a minimum.

All rations were of the simplified type and the one now used as a standard contains casein* 35 , starch 43 , lard 13 , cod liver oil $\dagger$ 2 , salts 4 , and cellophanet 3 . The earlier standard varied from this in some particulars, but as the differences are of no significance they are not described in detail. Yeast $\S$ was commonly used to supply the vitamin $B$ complex, replacing an equal weight of starch. As is described later the experimental diets included other vitamin carriers. One of these, the ether-extract of egg yolk, was substituted for lard, the others were substituted for starch.

It should be mentioned that chicks are highly variable, and it occasionally happens that an entire hatch is of low vitality and fails to grow normally regardless of the ration. For that reason it is desirable to have a positive control for every separate feeding trial. An unsatisfactory outcome may be due to subnormal animals instead of to an inadequate diet. We have used a ration that contains $40 \%$ of yeast as a control, but because of its high protein content the percentage of casein is reduced to 25 .

As another consequence of this variability it is necessary to use larger numbers than when studying the nutritional needs of the rat. If a ration is slightly inadequate some chicks will give no evidence whatever of a nutritional deficiency, while others will utterly collapse. We begin with chicks that appear to be healthy, but once selected none is discarded. With diets of the type we are using untoward symptoms seldom develop under 14 days, so we lay little stress on deaths that occur within that time. Some of

*Supplied by Lister Bros., New York ('ity.

†Supplied by F. L. Patch Co., Boston, Mass.

\$Supplied by the DuPont Cellophane Co., Buffalo, New Fork.

§Supplied by Wallerstein Co.. Inc., New York City. 
these are probably due to bacillary white diarrhea, others to causes that are more obscure.

When studying the requirements of chicks for growth they are kept under observation for 6 weeks only. It was formerly the custom to keep them for 16 weeks, but as time went on it became very clear that the third week is the critical period. If a chick is loing well at 6 weeks the chance that it will succumb later to a deficiency is exceedingly remote.

The Deficiencies of Yeast.-As mentioned before, Hogan and Shrewsbury ${ }^{3}$ had shown that our basal diet could be made adequate for the chick by increasing the amount of yeast up to $40 \%$ of the entire ration. Tentatively then, the earlier failures were ascribed to a deficiency of some member of the vitamin $\mathrm{B}$ complex, merely because the deficiency is not manifest if a sufficiently large quantity of yeast is used. However, a ration that contains $40 \%$ cf yeast can hardly be regarded as synthetic so it was decided to investigate other sources for the factor which is deficient in yeast. Previous experience had shown that it is present in relatively high concentration in various natural foodstuffs, the most promising of which were egg yolk, liver, and rice polishings. Renewed attempts were made, therefore, to extract the elusive factor from them and obtain it in soluble form, and in this endeavor yeast itself was included with the other sources. The solvents examined were chiefly alcohol, ether, and water. More strenuous chemical procedures also were tried, because of the possibility that the substances sought were held in combinations that do not yield to a mild extraction. Chief of these was hydrolysis, by strong acid. It was hoped that some of the resulting preparations might contain the factor sought in relatively concentrated form, and four of them offered some promise, acid-hydrolyzed yeast, the ether extract of egg-yolk, liver extract, and tikitiki.

The acid-hydrolyzed yeast (AHY) was prepared as follows: 600 grams of dried yeast were mixed with $2500 \mathrm{ml}$. of $9.6 \mathrm{~N}$ sulphuric acid in a 5-liter round bottom flask, and the mixture was refluxed on a sand bath for 24 hours at $109^{\circ} \mathrm{C}$. The acid was then neutralized with barium hydroxide, the barium sulphate removed, and the filtrate, at a $\mathrm{pH}$ of approximately 4.8 , was concentrated in an open vessel on a hot plate. The average yield of dry matter was about $35 \%$, but the actual concentration of the active agent was probably less than this figure would indicate. No effort was made to account for the other $65 \%$, but some of it was probably held in the barium sulphate precipitate, and the remainder was oxidized 
by the strong acid. N/2 acid was used in a few cases, but we have not yet attempted to decide which concentration is preferable.

More important than the degree of concentration is the question of the active principle or principles. Some of the vitamins of yeast are probably completely destroyed by the drastic procedure to which it was subjected, though there is no reliable estimate as to how many survive. It is also possible that some of the factors which survive the process may be adsorbed on the barium sulphate and thus be withheld from the filtrate. If it is true, as just postulated, that one essential factor of yeast is not readily extracted by the ordinary solvents, it is reasonable to suppose it is held in a relatively firm combination in an insoluble complex, and may be set free by

Table 1.-Acid-Hydrolyzed Yeast as a Vitamin Carrier

\begin{tabular}{|c|c|c|c|c|c|c|c|c|c|c|c|c|}
\hline \multirow{3}{*}{$\begin{array}{l}\text { Number } \\
\text { of Chicks }\end{array}$} & \multicolumn{4}{|c|}{ Chicks Living at Six Weeks } & \multirow{2}{*}{\multicolumn{4}{|c|}{$\begin{array}{l}\text { Number of } \\
\text { Mortalities }\end{array}$}} & \multirow{2}{*}{\multicolumn{4}{|c|}{$\begin{array}{c}\text { Number of } \\
\text { Abnormalities }\end{array}$}} \\
\hline & \multicolumn{2}{|c|}{ Males } & \multicolumn{2}{|c|}{ Females } & & & & & & & & \\
\hline & No. & $\begin{array}{c}\text { Av. Wt. } \\
\text { gms. }\end{array}$ & No. & $\begin{array}{c}\text { Av. Wt. } \\
\text { gms. }\end{array}$ & A & $\overline{\mathrm{B}}$ & $\mathrm{C}$ & $\mathrm{D}$ & $\mathrm{A}$ & $B$ & C & $\mathrm{D}$ \\
\hline \multirow{3}{*}{\multicolumn{4}{|c|}{ 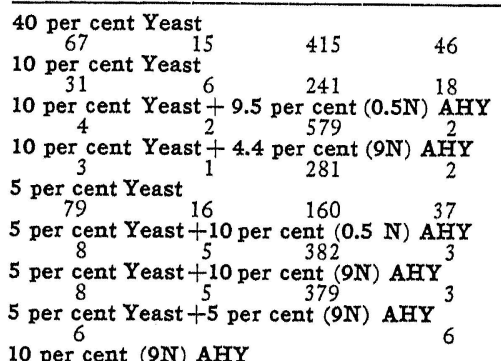 }} & 341 & & 11 & & 52 & 33 & $1^{4}$ & 1 & \\
\hline & & & & $\begin{array}{l}238 \\
448 \\
213\end{array}$ & 4 & & 1 & 2 & $\begin{array}{l}2 \\
1\end{array}$ & 6 & & 2 \\
\hline & & & & $\begin{array}{l}148 \\
322 \\
297 \\
246\end{array}$ & 1 & 2 & 1 & 22 & $\begin{array}{l}1 \\
2\end{array}$ & 3 & 1 & 1 \\
\hline
\end{tabular}

1 The only abnormality observed was curled toes; the cause of death was unknown.

2 Four of these were from a hatch of low vitality. The other died at 12 days.

3 One case of cart wheels, two of disturbed equilibrium.

${ }^{4}$ Walked with a quick, jerky step.

hydrolysis as a relatively simple compound. A summary of the results obtained when yeast was supplemented with acid-hydrolyzed yeast is presented in Table 1 . The exact composition of the rations is easily estimated by subtracting the total amounts of the vitamin carriers from the percentage of starch in the standard ration. Throughout this paper the percentages of soluble supplements are calculated on a dry matter basis. The letters A, B, C, D appear in legends under the figures, and in the headings of the tables and have the following significance. 
A inculdes all polyneuritic-like symptoms; head retractions, cart wheels, disturbed equilibrium, eye twitch, tremors, etc.

B includes the varied manifestations of "leg-weakness," paralysis of leg muscles, slipped tendons, enlarged joints, curled toes, weakness of hip joints which causes the chick to rest on the keel, deformed leg bones, etc.

C includes cases of diarrhea.

$\mathrm{D}$ includes all abnormalities of undetermined nature.

The rate of growth on moderate amounts of yeast, either 5 or $10 \%$ of the ration, is never satisfactory but is markedly accelerated by the addition of acid hydrolyzed yeast. In one case the ration contained $10 \%$ of yeast and $9.5 \%$ of the hydrolyzed product, and the rate of growth was astonishing. The two males averaged nearly 580 grams at 6 weeks, and the 2 females averaged a little less than 450 grams. When smaller amounts of either yeast or acid-hydrolyzed yeast were used, the growth rate was decreased. There were no mortalities among the 29 chicks that received these supplements but the abnormalities were not entirely eliminated. None of these rations, therefore, is regarded as a complete success.

The most remarkable feature of this series was the survival of one chick in the group that received a ration which contained $10 \%$ of acid-hydrolyzed yeast as the only source of the vitamin B complex. The other three chicks died of undetermined causes, but the rate of growth of this survivor was greater than that of those which received the basal ration, containing $5 \%$ yeast.

As mentioned before, dried $\mathrm{egg}$ yolk* offered some promise as a source of the substances sought, hence an attempt was made to prepare extracts from it. The only extract, however, which seemed useful for our purpose was obtained with ether, and is the only one described. This was prepared by filtering off the ether, and then allowing it to evaporate in an open dish at room temperature. The average yield was $50 \%$ by weight of the original dried egg yolk. Table 2 summarizes the trials in which the ether-extract was

Table 2.-Ether-extract of Egg Yolk as a Vitamin Carrier

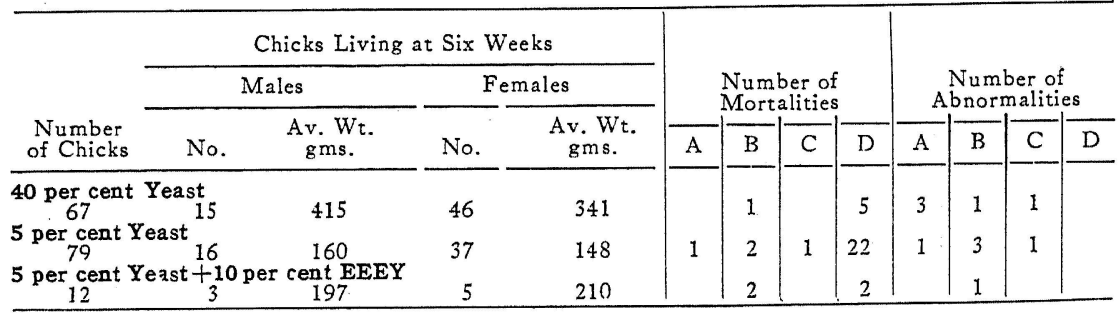

*Supplied by T. M. Duche and Sons, Inc., New York City. 
used as a supplement to yeast. In cvery trial the rate of growth was slightly increased but leg weakness always occurred. There were no cases of polyneuritis, but polyneuritis seldom occurs when the rate of growth is as slow as it was in these trials.

Tikitiki, prepared by the method of Wells ${ }^{24}$, had little effect on the growth rate, but was of some value in preventing abnormalities. When fed at the lower level, approximately $1 \%$ of the ration, three cases of leg weakness were noted but there were no disturbances when $2 \%$ tikitiki was supplied. Additional details are given in Table 3 .

Table 3.-Tikitiki as a Vitamin Carrier

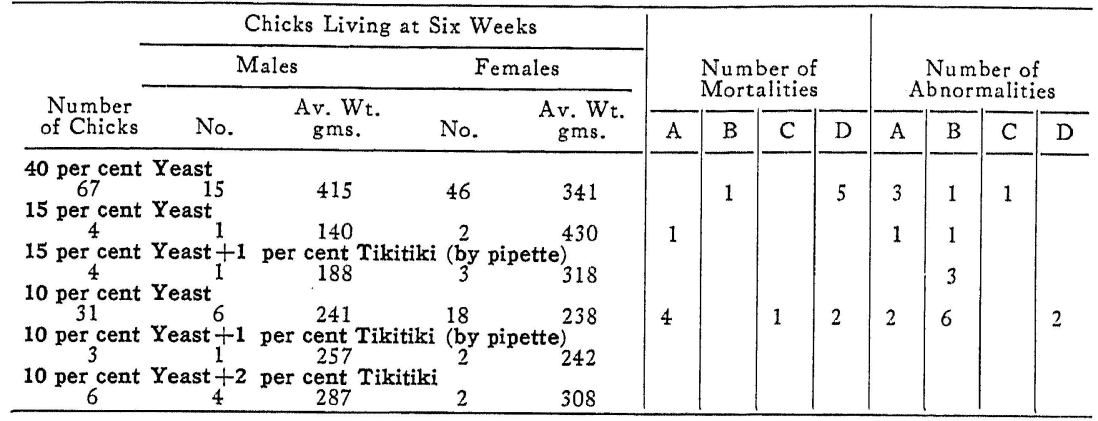

Two fractions ${ }^{1}$ of a liver extract were examined and one of these, our Laboratory Number 1376, proved entirely satisfactory in supplying the deficiencies of yeast. No. 1376 comes to us labelled "Purified Liver Extract," and is the fraction which is soluble in water and in $70 \%$ alcohol. It is used in the treatment of pernicious anemia. The other preparation, our No. 13\% r is the fraction precipitated by $70 \%$ alcohol from water solution during the preparation of No. 1376. The more important observations of this series are collected in Table 4.

The basal diet contained $5 \%$ of yeast and this was supplemented with varying proportions of the two liver extract fractions. A supplement of $10 \%$ of Extract $13 \% 6$ supported very rapid growth, and gave complete protection from any type of abnormality. When this amount was reduced to $5 \%$ the growth rate was markedly retarded, two chicks died, and one developed leg weakness. Fraction $137 \%$, proved to have little or no value as a supplement to yeast, but when combined with Fraction 1376 at a level of $5 \%$ of each, the combination was not much less effective than $10 \%$ of Fraction $13 \% 6$

1 We are much indebted to Dr. David Klein of the Wilson Iaboratories, (hicago, Illinois, for generously supplying us with these materials. 
alone. Our explanation is that Fraction $137 \%$ contains a small quantity of the same agents as are effective in Fraction 1376, and the effect is merely additive. When these two fractions were reduced in amount to $2.5 \%$ of each, the rate of growth was accelerated for a time, but finally every chick collapsed, and none survived. This phenomenon has been observed frequently, especially when liver extracts are used as supplements. The initial growth rate may be quite rapid, but if the amount of the extract is too small the mortalities will be much more numerous than in the basal groups which receive no extract at all.

Table 4.-Liver Extracts as Vitamin Carriers

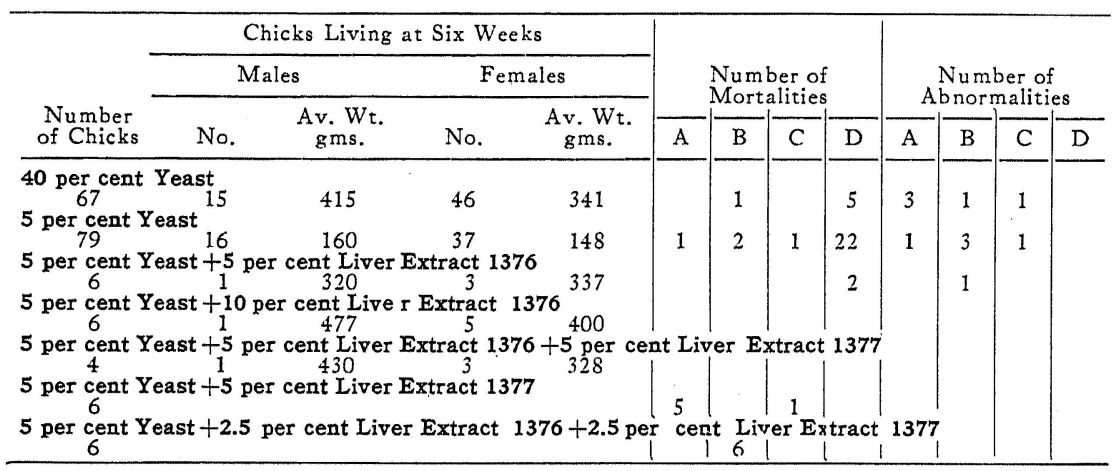

It is evident that rations containing either 5 or $10 \%$ of yeast are deficient in some factor or factors required to promote growth, prevent polyneuritis, or prevent leg-weakness. One such factor remains in yeast which has been hydrolyzed by strong acid, but though it accelerated the rate of growth it did not entirely eliminate polyneuritis or leg weakness. The ether-extract of egg yolk accelerated the rate of growth slightly, but seemed to be of no value in reducing the number of abnormalities. Small amounts of tikitiki seemed to prevent symptoms of polyneuritis, but not leg weakness. When larger amounts were supplied no abnormalities were observed but the rate of growth was not much accelerated. The only one of the supplements that contains all factors deficient in yeast is Liver Extract 13\%6. It is probably not a good source of one of them, however, for a small quantity does not prevent polyneuritis, though it does prevent leg-weakness and supports an excellent rate of growth. The minimum amount necessary to insure freedom from polyneuritis is somewhat less than 10\%. Examples 
of the various types of abnormalities we have observed are shown in Figs. 4 to $\%$.

The Deficiencies of a Water Extract of Yeast.-The numerous publications that indicate the great complexity of vitamin $B$, as now understood, appeared while our work was in progress. If the members of this complex are as numerous as has been indicated recently it is evident that the problems of the nutrition of the chick are more difficult than had been supposed. Furthermore, even if an extract were obtained which would make a simplified diet adequate for the chick when combined with yeast, the practical application of such a discovery would still be very difficult. It seemed necessary then to obtain all the supplements required by the chick in soluble form. The way would then be open to further concentration, and possibly to more complete isolation.

It was decided, therefore, to return to the water extract of yeast which had proven promising in our earlier studies. This extract was prepared by the following method. Twenty gallons of distilled water were heated to boiling, and 6800 grams of dried yeast were added slowly with vigorous stirring to prevent the formation of lumps. Glacial acetic acid was added until the reaction was just acid to litmus, the amount necessary being about $20 \mathrm{ml}$. After 24 hours the supernatant liquid was siphoned off and condensed under reduced pressure, at a temperature ranging from 60 to $70^{\circ} \mathrm{C}$. The abbreviation OWE was used to designate the final product. In the beginning this was prepared from fresh yeast, and was quite dependable but our recent preparations have not been reliable, possibly because we started with dry yeast. On the basis of dry matter content $20 \%$ of the water extract is equivalent to $4.0 \%$ dried yeast, but neuritis and leg weakness were common on the former preparation and were seldom observed on the latter. An effort was made, therefore, to determine whether any of the soluble supplements we had prepared could be added to the water extract to make a satisfactory combination. The liver extracts and tikitiki proved valueless, and the improvement due to the ether-extract of egg yolk was not great. On the other hand acid-hydrolyzed yeast was very promising. The more important observations are recorded in Table 5 .

Table 5 shows that $20 \%$ water extract sustains less rapid growth than does $40 \%$ of yeast and that it is less effective in preventing disturbances of all kinds. When the amount of the water extract is decreased from 20 to $5 \%$ the growth 
Table 5.-Water-extract of Yeast and Hydrolyzed Yeast as VITAMIN CARRIERS

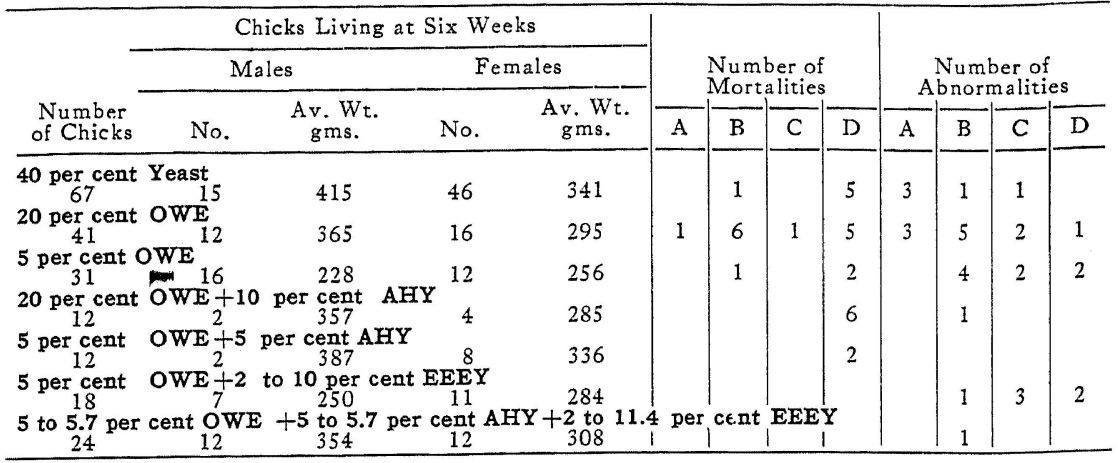

rate is reduced, but it may seem anomalous that the incidence of all untoward symptoms is also reduced. That, however, is a common experience in experimental chick feeding. If a ration is somewhat inadequate, but permits a rapid initial growth rate, it is more fatal than a still less adequate ration which never sustains a rapid rate of growth. The mortality on $20 \%$ of the water extract plus $10 \%$ of hydrolyzed yeast was high, but we are convinced such large amounts are slightly toxic. In some instances it seemed that $10 \%$ of hydrolyzed yeast alone was somewhat toxic. When the amount of each supplement was reduced to $5 \%$ of the ration the rate of growth was satisfactory and the mortalities were reduced.

The ether extract of egg yolk seemed to fortify the water extract in some degree, so all three supplements were combined in one ration. There was some reason to believe that this was a better combination than the water extract plus hydrolyzed yeast alone. The growth rate was not increased, but there were no mortalities, though there was one case of leg weakness.

It will be noted that in the last two sets of observations shown in Fig. 5 the amounts of the supplements used were not constant. Inasmuch as the growth rate was not appreciably affected by variations within the limits indicated, similar feeding trials were combined in this presentation.

The Adequacy of Soluble Vitamin Supplements.-Since the acid-hydrolyzed yeast seemed to contain some factor which is deticient in the water extract, an effort was made to dispense with the latter altogether. All of the other soluble supplements which had at some time given evidence of containing an active agent were combined in varying proportions in one ration. The results were altogether satisfactory.25 for such a combination is entirely ade- 


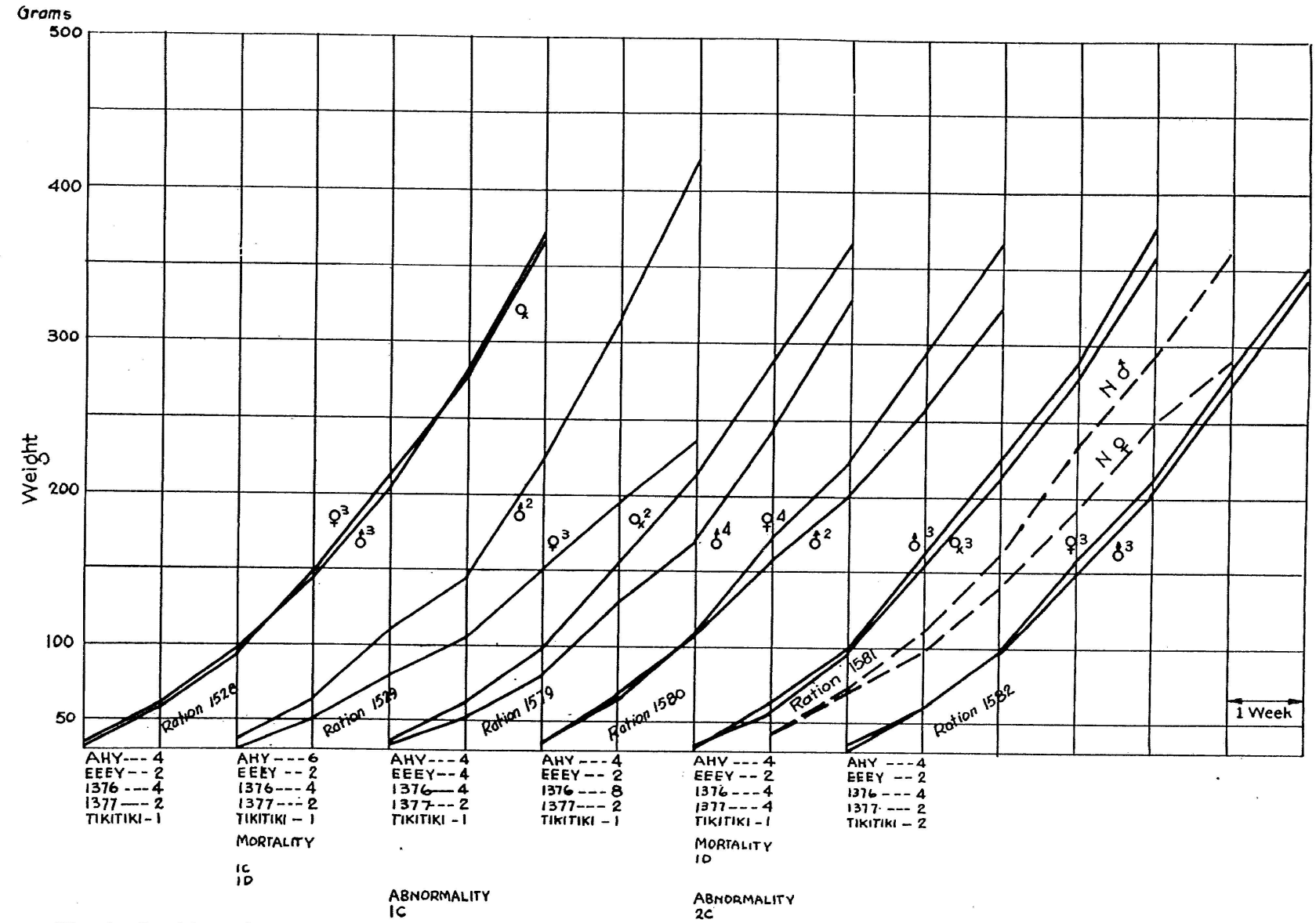

Fig. 1.- In this series each supplement of Ration 1529 was doubled singly. An exception occurs in Ration 1529 where A. H. Y. was increased to only 6 per cent due to indications that larger amounts are toxic. Neitler polyneuritis nor leg weakness occurred in the series. Increasing any supplement rafled to accelerate the rate of growth. It was concluded that the requirement of the
chick, for the active material contained in any of the supplements, wis satisfied by the quantities supplied in Ration 1528. 


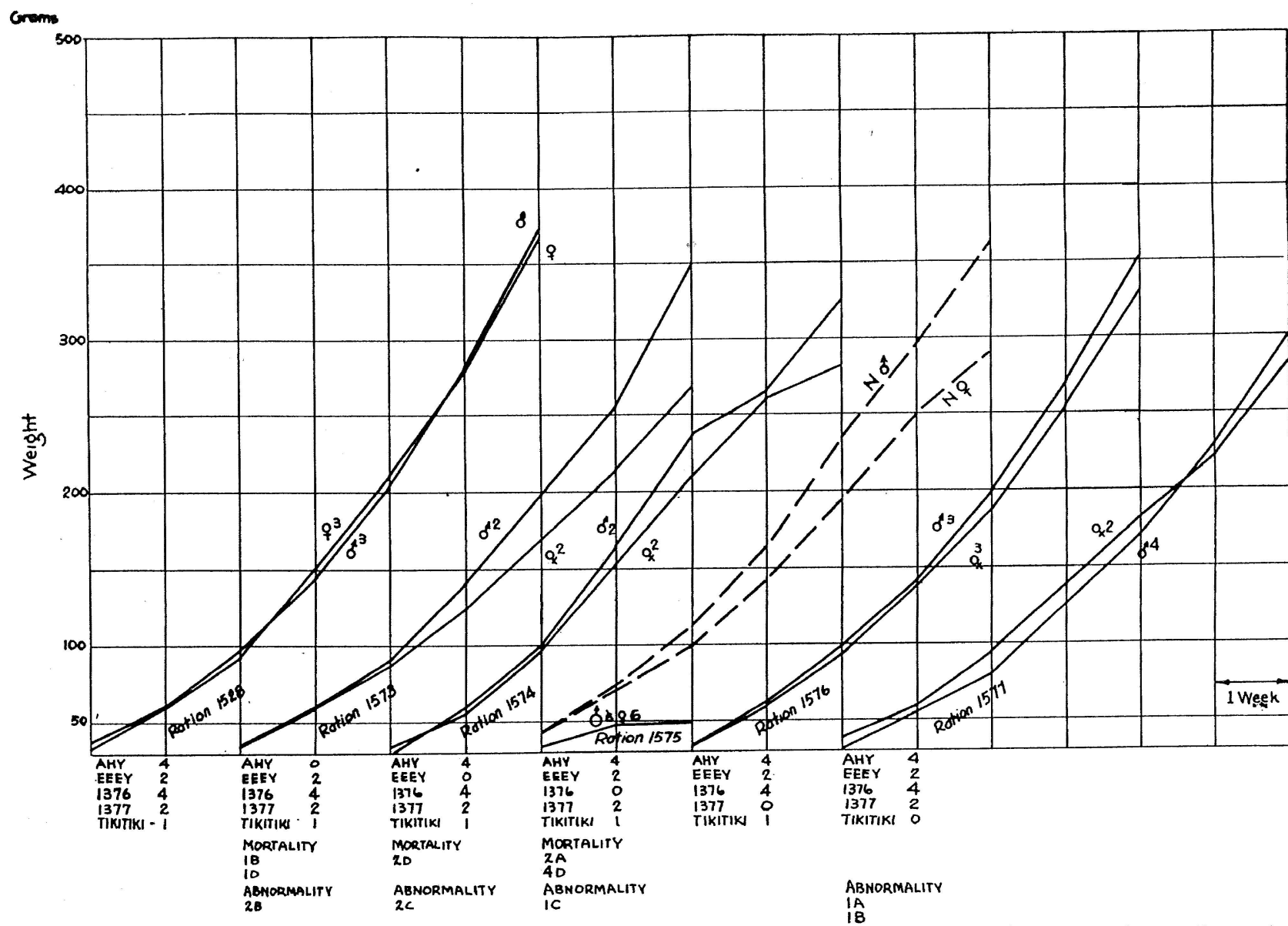

Fig. 2-Using Ration 15 S a gain as the control, one supplement was omitted from each of the other rations. The contro group grew at an excellent rate and was free from abnormalities. Each ration from which a supplement was omitted promoted a

slower rate of growth or failed to prevent polyneuritis or leg weakness. This indicates that either each supplement carries one
vitanuin in relatively large amounts or that some, or all, of the ritamins are more or less distributed in all of the suppleinents. 


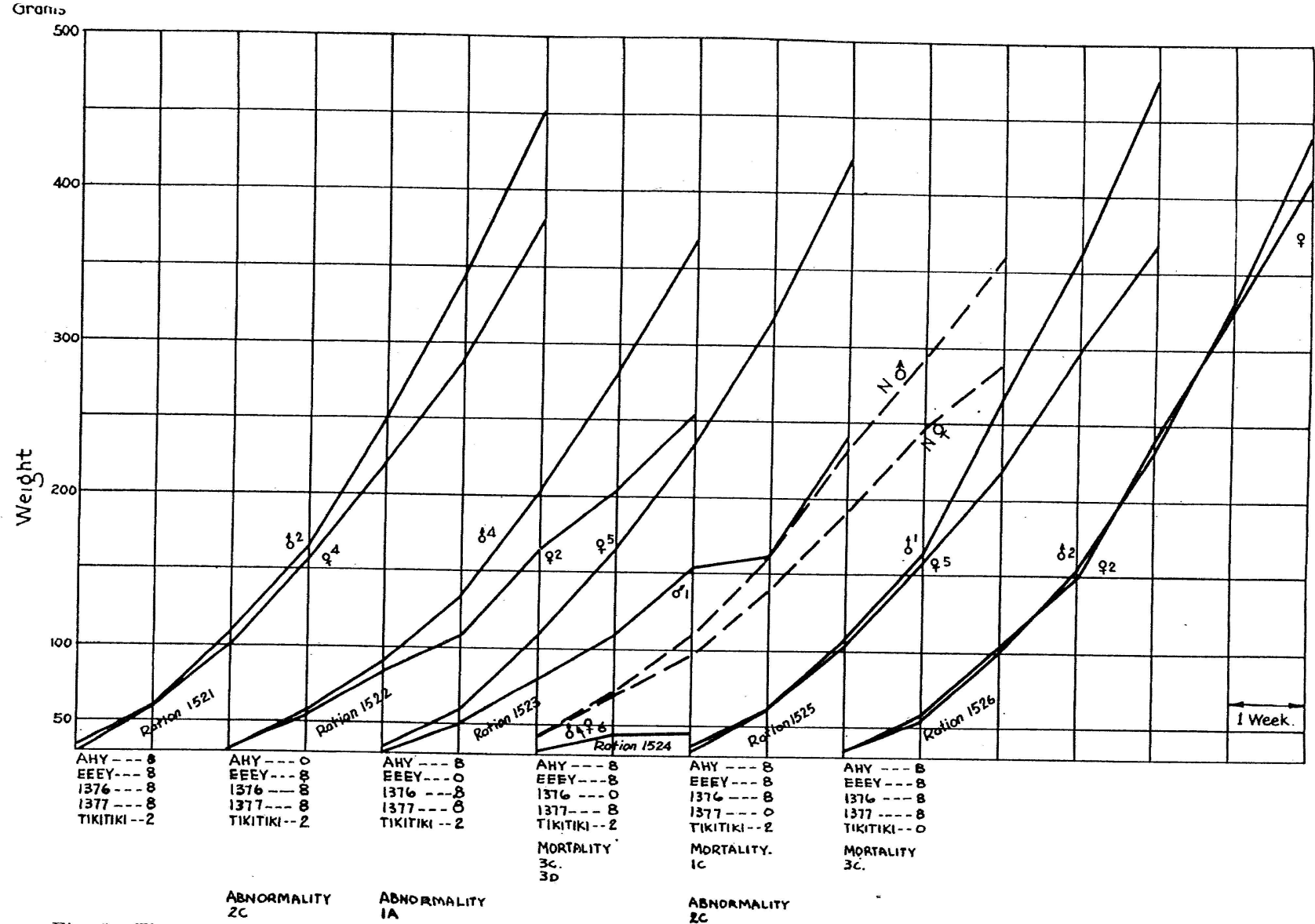

Fig. 3.-The control, Ration 1521 , contained from two to fum $2 C$

Fiss. 1 and 2, Ration 1528. The five accompanying two to four times the amount of each supplement found in the control of sitisfactory as when all the supplements were ing rations have one supplement omitted from each. The results were never as

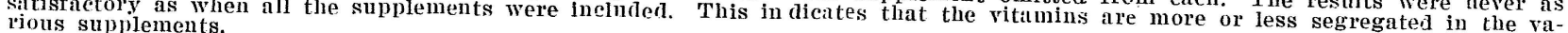




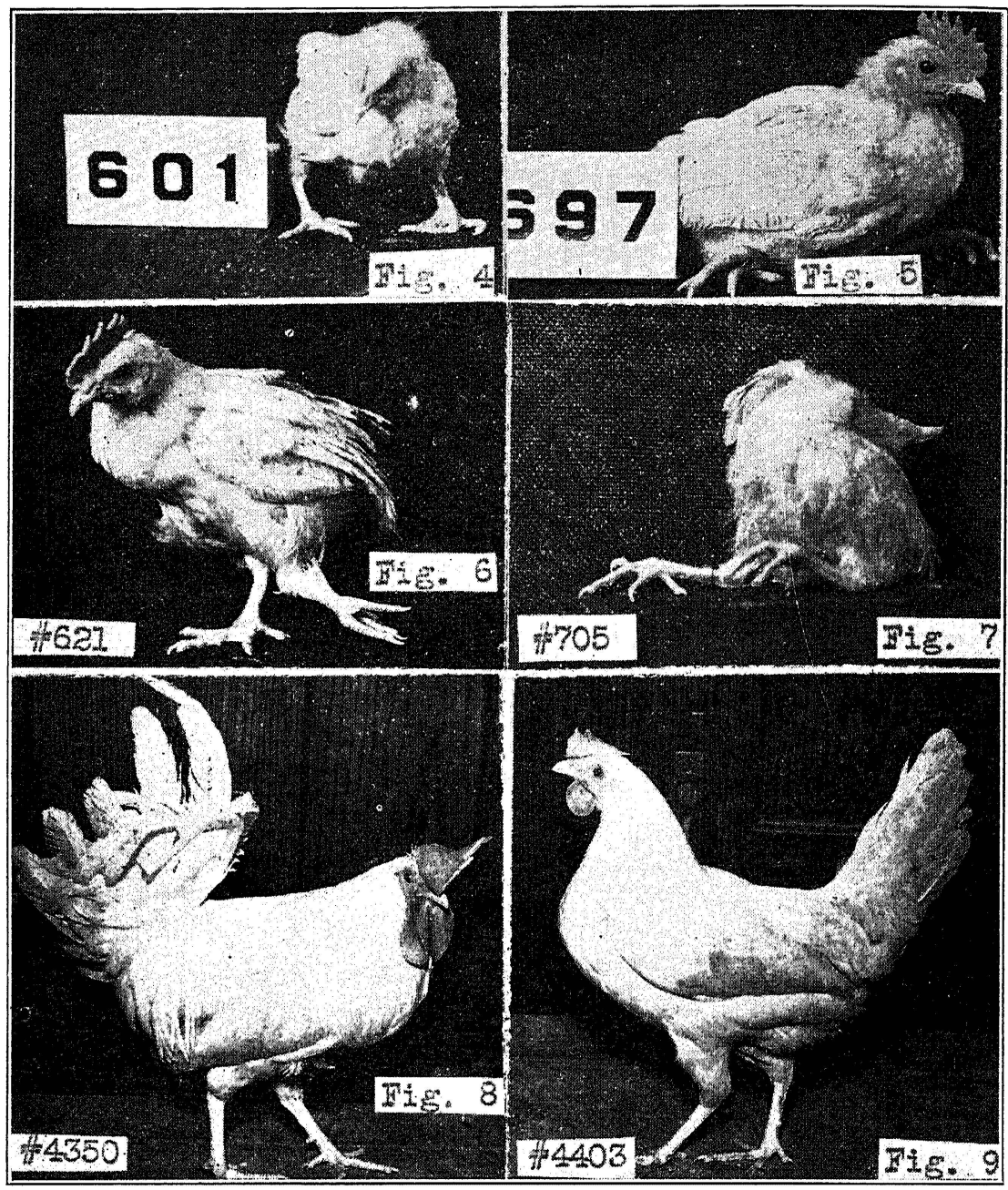

Fig. 4.-No. 601, age 44 days, weight 135 grams, male. Ration contained 5 per cont yeast. Iees deformed, toes on left foot curled inward.

Fin. 6.-No. 621, same aze, weight, and sex as No. 697 , and received the same ration. I.en bones crooked, "slipperl tenclon" in left leg, and joint greatly en larged.

Fig. S.-No. 4350, age 143 days, weight 1 s 80 grams. male. Secuna seneration on simplified diet.
Fig. 5.--No. 697, age 44 days, weight 2St grims, male. Ration contained 10 per cent veast. Leg bones crooked and "slipped tendon" in both legs.

Fig. 7.-No. 705, age 27 days, weight 147 arams, male. Ration contained 10 per cent yeast. Extreme head retraction. The chick was falling backwards when the photograph was taken. This is typical of cases classified by us as chick polyneuritis.

Fig. 9.-No. 4403, age 165 days, weight 1330 grams, female. Second generation on simplified diet. Began laying at 170 days, laid 17 eggs in next 21 days. 
quate in rearing chicks to maturity. This mixture contains acidhydrolyzed yeast, ether-extract of egg yolk, Liver Extract 13\%6, Liver Extract $137 \%$, and tikitiki.

The purpose of the next procedure was to determine the minimum amounts of each of these supplements required to sustain satisfactory growth and normal bodily vigor. Fig. 1 describes graphically some of the results obtained in determining these quantities. The broken lines on all the charts, representing normal growth rates, were plotted from the data of Buckner, Wilkins, and Kastle ${ }^{26}$.

Ration 1528, which met our requirements admirably, has the following percentage composition: Casein 35, starch 32, lard 11, cod liver oil 2 , salts 4 , cellophane 3 , acid-hydrolyzed yeast 4 , etherextract of egg yolk 2, Liver Extract-1376 4, Liver Extract-137\% 2, and tikitiki 1. It developed later that when the ration contains $2 \%$ of the ether-extract of egg yolk the growth rate will not be decreased if cod liver oil is omitted entirely. If this is done the total quantity of vitamin carriers amounts to $13 \%$ of the ration. Undoubtedly some of these supplements, if not all of them, can be concentrated still further. It will be noted that each supplement is increased in one of the other rations shown in Fig. 1, but in no case was a better growth rate obtained. This convinced us that unless the preparations deteriorated, larger amounts need not be used. The attempts to reduce markedly the amount of any one of the supplements included in Ration 1528 were more or less uniformly unsuccessful.

The possibility was suggested that some of these adjuvants may supplement each other quantitatively, and the results would be equally good if one were omitted. Some of our observations on this point are presented graphically in Figs. 2 and 3.

In Fig. 2 it will be observed that Ration 1528 was altered by omitting, one at a time, each of the supplements mentioned. In every case except when Liver Extract 1377 was omitted the growth rate was lowered and abnormalities of some sort appeared. In Fig. 3 this procedure was varied by greatly increasing the other supplements when any one was omitted. In every case there was an increase in either the mortality or the incidence of abnormalities, and usually the growth rate was reduced.

An examination of all our data has led us to believe that hydrolyzed yeast, the ether-extract of egg yolk, and tikitiki are practically inclispensable. When any one of these is removed some chicks may grow exceedingly well, but it is very 
seldom that some untoward symptoms do not develop. Liver Extract 13\%6, however, is absolutely indispensable. The mortality was practically $80 \%$ when this preparation was omitted, and even when the other supplements were greatly increased the mortality was not much reduced. We are still in considerable doubt that Liver Extract 1377 has any real value for our purpose. In some instances the chicks did as well without it, but in others they did not. Our present opinion is, that whatever may be the number of active agents in these preparations, they are present in both fractions, and present in much larger amount in No. 1376 than in No. 137\%. A summary of all our observations is given in Table 6.

Table 6.-The Adequacy of Soluble Supplements ${ }^{1}$

\begin{tabular}{|c|c|c|c|c|c|c|c|c|c|c|c|c|}
\hline \multirow[b]{3}{*}{$\begin{array}{l}\text { Number } \\
\text { of Chicks }\end{array}$} & \multicolumn{4}{|c|}{ Chicks Living at Six Weeks } & \multirow{2}{*}{\multicolumn{4}{|c|}{$\begin{array}{l}\text { Number of } \\
\text { Mortalities }\end{array}$}} & \multirow{2}{*}{\multicolumn{4}{|c|}{$\begin{array}{l}\text { Number of } \\
\text { Abnormalities }\end{array}$}} \\
\hline & \multicolumn{2}{|c|}{ Males } & \multicolumn{2}{|c|}{ Females } & & & & & & & & \\
\hline & No. & $\begin{array}{l}\text { Av. Wt. } \\
\text { gms. }\end{array}$ & No. & $\begin{array}{l}\text { Av. Wt. } \\
\text { gms. }\end{array}$ & A & B & C & $\mathrm{D}$ & A & $\mathrm{B}$ & C & $\bar{D}$ \\
\hline & 56 & 316 & & 1 & 9 & 8 & & 2 & 14 & \\
\hline \multicolumn{3}{|c|}{$\begin{array}{l}\text { AHY +EEEY +L1376+L1377+TT } \\
125=361 \\
\text { EEEY } 51376+\mathrm{L} 1377+\mathrm{LT}\end{array}$} & 5 & 288 & & 1 & 4 & 1 & & 2 & 2 & \\
\hline \multicolumn{3}{|c|}{ 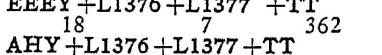 } & 12 & 306 & & 2 & 2 & 8 & 2 & 3 & 2 & 3 \\
\hline \multicolumn{3}{|c|}{$\mathrm{AHY}+\mathrm{EEEY}+\mathrm{L} 1377+\mathrm{TT}$} & 5 & 278 & 5 & & 4 & 14 & & & 1 & \\
\hline $\mathrm{AHY}+\mathrm{EE}$ & & ${ }^{2 T}{ }_{313}$ & 20 & 271 & & 2 & 1 & 4 & & & 4 & 1 \\
\hline $\mathrm{AHY}+\mathrm{EEI}$ & $-\mathrm{I}_{11} 376$ & $\begin{array}{r}1377 \\
295\end{array}$ & 6 & 315 & 2 & & 3 & & 2 & 4 & & \\
\hline
\end{tabular}

1 Whenever any of the various supplements were included in a ration, the minimum percentages offered were, acid-hydrolyzed yeast 4 , ether-extract of egg yolk 2, Liver Extract-1376 4, Liver Extract13772 , tikitiki 1 . In some instances larger quantities were supplied, but as they did not accelerate the growth rate consistently each combination is presented in one average, regardless of modifications in the amounts of these various components.

Because of the great importance which has been attached to the amounts of calcium and phosphorus consumed by chicks we have analyzed our rations for these elements. Ration 1528 contains $0.48 \%$ calcium and $0.42 \%$ phosphorus, and all the other rations of this series contained very similar amounts of these elements. As was mentioned in the introduction it is commonly believed that the ratio of calcium to phosphorus should be much larger than this, and since the percentages of both are very low an adjustment was made by replacing $2.4 \%$ of the corn starch with $1.3 \%$ calcium carbonate and $1.1 \%$ monobasic sodium hydrogen phosphate. This increased the ratio to three of calcium to two of phosphorus and increased the percentages to 1.00 and 0.67 respectively. The incidence of abnormalities was neither increased nor decreased in numerous trials with rations thus adjusted, so the use of additional carriers of calcium and phosphorus was discontinued. Our original purpose was to devise a simplified diet that is 
adequate for the chick, and we believe this is accomplished in Ration 1528. However, the vitamin carriers in this ration amount to a total of $13 \%$, which is somewhat higher than may seem suitable for this type of ration. An attempt was made, therefore, to concentrate the various supplements still further and some success has been attained. If the hydrolyzed yeast is extracted with strong alcohol about half the dry matter goes in solution and the soluble fraction apparently contains all the vitamin activity. The etherextract of egg yolk was saponified, and the non-saponifiable fraction was included in the ration instead of the ether-extract. This substitute seemed to be as active as the original extract, and reduced the amount of extraneous material by nearly $2 \%$. Approximately 0.12 grams of the non-saponifiable fraction are obtained from 2 grams of the ether extract. A fuller's earth adsorbate was prepared from tikitiki which seemed to be as useful for our purpose as the untreated solution. The adsorbate was as effective as an equal weight of dry matter in the original solution.

No extended effort has been made as yet to concentrate further the liver extracts, but our preliminary attempts failed almost completely. These studies are being continued. As yet these three substitutions have been studied in detail only when introduced singly, and it remains to be seen whether they can all be made simultaneously without lessening the adequacy of the ration. Preliminary studies have indicated such rations can be used successfully. If these results are confirmed the percentages of the supplements would be as follows: Alcohol-soluble fraction of hydrolyzed ycast 2, the non-saponifiable fraction of the ether-extract of egg yolk 0.12 , Liver Extract-1376 4, Liver Extract-137\% 2, and activated fuller's earth from tikitiki 1 , a total of $9.12 \%$. If the weight of the fuller's earth is deducted the total is considerably less than 9 . It is hoped that further concentration and isolation may be accomplished.

In order to obtain additional evidence of the adequacy of these soluble vitamin supplements, a few chicks of each sex have been reared to maturity to see if the ration is adequate during the reproductive period. It developed that a ration may sustain rapid growth but be deficient for a hen while producing eggs. Some of the supplements were increased in subsequent trials, and in all, 11 healthy chicks of the second generation were obtained. A female of this group began laying at 170 days of age, and in the next 21 clays laid 17 eggs, but sufficient time has not elapsed as yet to determine whether a third generation can be obtained. The ration 
now used during the reproductive period contains casein 35 , starch $2 \%$, butter fat $\%$, cod liver oil 1 , wheat germ oil 1 , salts 4 , tri-calcium phosphate 1 , cellophane 3 , acid-hydrolyzed yeast 4 , ether-extract of egg yolk 6, Liver Extract-13\%6 6, Liver Extract-13\%7 4, and tikitiki 1. A complete report of these observations will appear in a subsequent publication. Photographs of two of the second generation chicks are reproduced in Figs. 8 and 9.

\section{BIBLIOGRAPHY}

1. Hogan, A. G., Guerrant, N. B., and Kempster, H. I. 1925. Mo. Agr. Exp. Sta. Res. Bul. No. 81. J. Biol. Chem. 1xiv, 113.

2. McFarlane, W. D., Graham, Jr., W. R., and Hall, G. E. 1931. J. Nutr. iv, 331 .

3. Hogan, A. G., and Shrewsbury, C. L. 1930. J. Nutr. iii, 39.

4. Peters, R. A. Chemistry at the Centenary (1931) Meeting of the British Association for the Advancement of Science. p. 134. W. Heffer and Sons Ltd. Cambridge 1932.

5. Hogan, A. G., Shrewsbury, C. L., and Kempster, H. L. 1929. Mo. Agr. Fxp. Sta. Res. Bu1. No. 122.

6. Hogan, A. G., Shrewsbury, C. L., and Kempster, H. L. 1929. Mo. Agr. Fxin. Sta. Res. Bul. No. 124.

7. McCarrison R. Indian Med. Res. Mem. No. 10, 1928. Cited in Vitamins: A Survey of Present Knowledge. His Majesty's Stationery Office, London, 19.32, p. 124.

8. Pappenheimer, A. M., and Goettsch, Marianne. 1931. J. Exp. Med. 1iii, 11.

9. Norris, L. C., Heuser, G. F., and Wilgus, Jr. H. IS. 1930. Poultry Science ix, 133.

10. Norris. L. C.. Heuser, G. F., Wilgus, Jr., H. S. and Ringrose, A. T. 1931. Poultry Science $x, 93$.

11. Titus, H. W. 1932 . Poultrv Science xi, 117.

12. Bethke, R. M., Record, P. R. and Kennard D. C. 1931. Poultry Science x. 3.55 .

13. Hart, E. B., Kletzien, S. W. F., Scott, H. T., and Halpin, J. G. 1930. Poultry Science ix, 308.

14. Ha1l. G. F.. and King, E. T. 1931. Poultry Science x. 259.

15. Hunter, J. E.. and Funk, E. M. 1930. Proc. of 22nd Annual Meeting Poultry Science Assoc., (MacDonald College, Quebec, Canada), p. 45.

16. Payne, I. F., Hughes, J. S., and Lienhardt, H. F. 1932. Poultry Science xi, 158.

17. Herner, M. C., and Robinson, A. D. 1932. Poultry Science xi, 283.

18. Parkhurst, R. T., and McMurray, Mary R. 1932. J. Agr. Sci. xxii, 874.

19. Bethke, R. M., and Record, P. R. 1933. Bimonthly Bull. Ohio Agr. Exp. Sta. xviii, 48.

20. Hart, E. B., Scott. H. T., Kline, O. L., and Halpin, J. G. 1930. Poultry Science ix, 296.

21. Bethke R. M.. Kennard. D. C., Kick, C. H., and Zinzalian, G. 1929. Poultry Science viii, 257.

22. Holmes. A. D., and Pigott, Madeleine G. 1931. J. Ind. Eng. Chem. xxiii, 190.

23. Wilgus, Jr., H. S. 1931. Poultry Science x, 107.

24. We1ls, A. H. 1921. Phi1. J. Sci. xix. 67.

25. Hogan, A. G., and Boucher R. V. 1931. Proc. Am. Soc. Animal Production, p. 45.

26. Buckner. F. D., Wilkins, R. H., and Kastle, J. H. 1918. Am. J. Physiol. xlvii, 393. 